
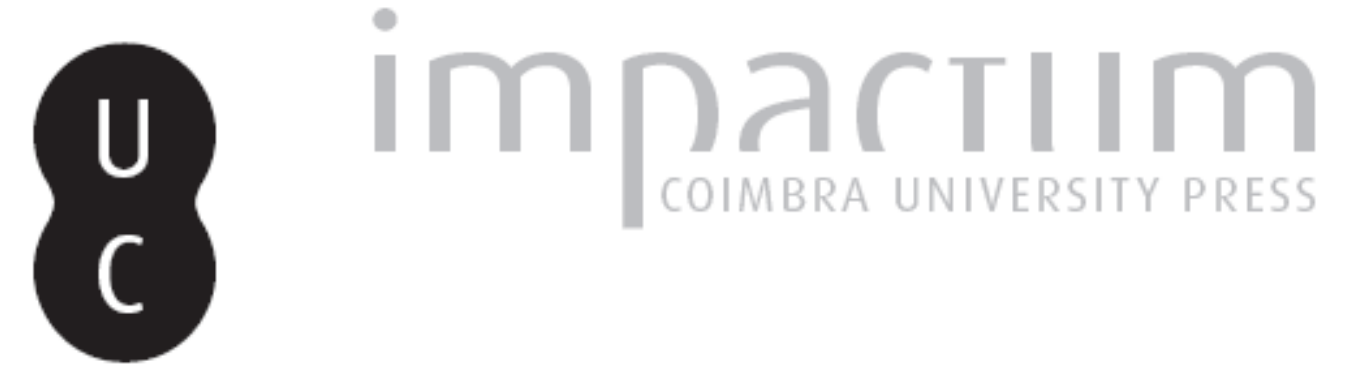

\title{
Violência e universo rural no Império do Brasil: historia e historiografía
}

Autor(es): Motta, Márcia Maria Menendes

Publicado por: Instituto de História Económica e Social; Imprensa da Universidade de Coimbra

URL persistente:

URI:http://hdl.handle.net/10316.2/44494

DOI:

DOI:https://doi.org/10.14195/0870-4147_37_2

Accessed : $\quad$ 26-Apr-2023 07:35:42

A navegação consulta e descarregamento dos títulos inseridos nas Bibliotecas Digitais UC Digitalis, UC Pombalina e UC Impactum, pressupõem a aceitação plena e sem reservas dos Termos e Condições de Uso destas Bibliotecas Digitais, disponíveis em https://digitalis.uc.pt/pt-pt/termos.

Conforme exposto nos referidos Termos e Condições de Uso, o descarregamento de títulos de acesso restrito requer uma licença válida de autorização devendo o utilizador aceder ao(s) documento(s) a partir de um endereço de IP da instituição detentora da supramencionada licença.

Ao utilizador é apenas permitido o descarregamento para uso pessoal, pelo que o emprego do(s) título(s) descarregado(s) para outro fim, designadamente comercial, carece de autorização do respetivo autor ou editor da obra.

Na medida em que todas as obras da UC Digitalis se encontram protegidas pelo Código do Direito de Autor e Direitos Conexos e demais legislação aplicável, toda a cópia, parcial ou total, deste documento, nos casos em que é legalmente admitida, deverá conter ou fazer-se acompanhar por este aviso.

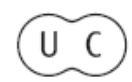




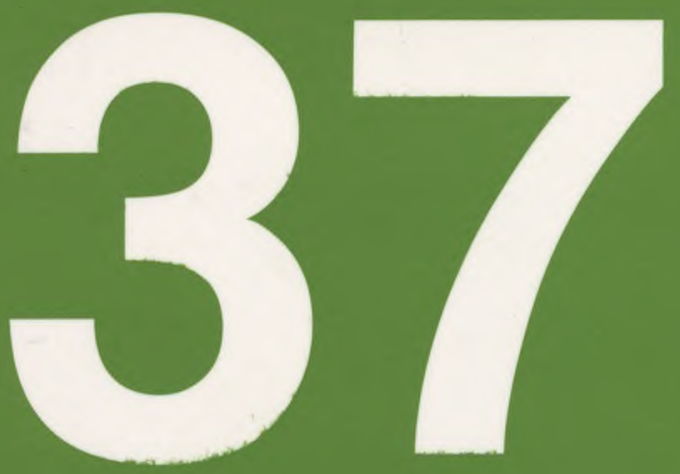

Revista Portuguesa de História

Faculdade de Letras da Universidade de Coimbra Instituto de Historia Econónica e Samial

Coimbra 05 
Revista Portuguesa de Historia

t. XXXVII (2005)

pp. 29-43

\title{
Violência e Universo Rural no Império do Brasil: Historia e Historiografía*
}

\author{
MÁRCIA Maria Menendes MotTA \\ Universidade Federal Fluminense
}

Os embates sobre as formas de aquisição e distribuição da propriedade da terra no Brasil tem sido objeto de múltiplas interpretações. Por um lado, há sempre a necessidade de se discutir as questões que envolvem a concentração da propriedade nas mãos dos fazendeiros, o que implica analisar o fenômeno da grilagem e a busca da auto-preservação dos terratenentes. Por outro, os embates pautam-se nas questões que envolvem a chamada função social da propriedade e o direito a terra, num país de dimensões continentais. A despeito das inúmeras formas de se encarar o problema, podemos inferir que há uma luta marcadamente violenta, opondo fazendeiros e lavradores, luta essa que atravessa a história da ocupação de terras no país.

Esta luta tem sido objeto de pesquisa de muitos cientistas sociais e fonte de inspiração dos principais estudiosos sobre o tema. A análise acerca da bibliografia acerca dos movimentos rurais no Brasil do século XIX, eixo central do presente artigo, ajuda-nos a refletir sobre os porquês de uma determinada amnésia social

- Uma primeira versão deste artigo foi publicada na revista: Estudos. Sociedade e Agricultura. Do programa de pós graduação em Desenvolvimento, Agricultura e Sociedade (CPDA), da Universidade Federal Rural do Rio de Janeiro, em abril de 2001. 
sobre os conflitos rurais de outrora e nos lança luz sobre novas possibilidades de pesquisa em sua relação com uma nova abordagem, oriunda da chamada nova esquerda britânica.

Nas últimas décadas, a historiografia européia sofreu a influência irrefutável dos trabalhos de E. Thompson, historiador inglês, responsável por um novo enfoque acerca dos motins ingleses do século XVIII e por uma nova concepção do papel da justiça, do costume e das leis em sua vinculação aos movimentos sociais. Ao ressaltar o papel decisivo da cultura, o pesquisador buscou uma aproximação crescente com as contribuições da antropologia, no intuito de compreender o passado para além dos elementos de natureza sócio-econômica (Thompson, 1979,1987, 1998).

Não foi menos intenso o impacto causado, na historiografia brasileira, pela leitura dos textos de Thopmson. Na verdade, o crescente predomínio da chamada nova esquerda britânica (além de Thompson, Hobsbawm, Christopher Hill entre outros) foi responsável pelo revigoramento de muitos dos temas de destaque da história social como, por exemplo, a escravidão. A polêmica envolvendo Silvia Lara e Sidney Chalhoub versus Jacob Gorender, deu o tom dos debates - por vezes calorosos - acerca das visões sobre o papel do escravo na sociedade dos oitocentos.

Para Silvia Lara, os anos 80 marcaram uma revitalização de estudos sobre a escravidão e sobre a abolição no país. Estes estudos não são um bloco monolítico e apresentam diferenças marcantes na forma de abordar os temas relativos à escravidão. No entanto, pode-se verificar que há neles um esforço em discutir como os cativos buscaram - a despeito de sua condição - estabelecer certos direitos, "transformando as próprias relações de dominação a que estavam submetidos" (Lara, 1992:232). Para Gorender, ao contrário, os trabalhos daquele período devem ser conhecidos enquanto estudos reabilitadores da escravidão. Ao defender que tais estudos marcam uma visão patriarcalista da escravidão, Gorender reforça a noção da coisificação do cativo, como elemento fundamental para se compreender a sociedade colonial. "Recusar que havia coisificação social é recusar que havia escravidão" (Gorender, 1992:. 251).

Para além do debate e das polêmicas entre as posições, não se pode negar que há de fato uma expressiva e importante produção acadêmica de viés thompsoniano sobre a escravidão, cujo enfoque está centrado em experiências do cativeiro e ardis adotados pelos escravos na sua luta pela sobrevivência. Os estudos de Chalhoub, (Chalhoub, 1990,1996) e as contribuições mais recentes de Soares $(1999,2001)$ são exemplos emblemáticos de uma forma de conceber, não somente o modo de vida dos cativos e da plebe urbana, mas, sobretudo, uma determinada concepção de história. 
As coisas são um pouco mais complicadas quando nos referimos aos homens livres e pobres do campo. Quando nos referimos ao universo rural de outrora, é ainda comum a ênfase numa visão bipolar que ressalta a oposição entre fazendeiros e cativos, minimizando as múltiplas contribuições dos homens livres e pobres.(Motta, 1998b) Este últimos, são ainda vistos como pouco expressivos e no limite, sem razão de ser. Ao homem pobre do campo do século XIX, não lhe é atribuída nenhuma capacidade de construir uma cultura plebéia e experiências de resistência à opressão.

Ë importante destacar, no entanto, os estudos realizados por um grupo dedicado à História Social da Agricultura do programa de Pós Graduação de História da Universidade Federal Fluminense que, ao longo das décadas de 80 e 90, desenvolveu uma série de dissertações e teses sobre aqueles homens do século XIX. Ao questionar muitas vezes o chamado paradigma paulista acerca da via única sobre a transição do trabalho escravo para o livre, os pesquisadores mostraram diversidade das formas de inserção social do homem livre na sociedade escravista. Assim, os estudiosos fluminenses demonstraram que não houve um único processo de transição. Em algumas áreas, a substituição do trabalho escravo pelo livre deu-se pela incorporação do imigrante. Em outras, a substituição do ex-cativo deu-se pela inserção do ex-escravo enquanto trabalhador livre, submetido de diversas formas ao grande fazendeiro. Para estes pesquisadores, longe de se pensar numa tradição à paulista - daí a noção de paradigma - é necessário entender a multiplicidade e estratégias no processo de substituição do cativo.

Cabe aqui ressaltar o pionerismo do estudo de Francisco Carlos Teixeira da Silva que em 1981 defendeu a dissertação: Camponeses e criadores na formação social da Miséria (1820-1920). Nesse trabalho, Teixeira da Silva anteciparia algumas das discussões que se tomaram recorrentes na mencionada linha de pesquisa. A partir daí, muitos dos trabalhos redefiniam o universo rural do oitocentos, complexifícando as relações sociais ali existentes e impulsionando as análises sobre a dinâmica do mercado intemo e as relações de trabalho existentes no universo rural do país.

No entanto e naqueles anos, as questões envolvidas nas pesquisas estavam, na maioria das vezes, direcionadas a uma história económica do mundo rural, onde os problemas da quantificação e construção de tipologías e modelos assumiam um papel preponderante nas diversas abordagens. Além disso, os trabalhos de Kautsky, as contribuições de Chayanov tomavam-se leituras obrigatórias, incorporando muitos dos debates e dilemas então vivenciados pela sociologia rural.

A influência de Kautsky e Chayanov e de tantos outros ligados à sociologia rural era em grande parte resultado da divulgação das pesquisas e das orientações de Maria Yedda Leite Linhares. Os esforços no sentido de consolidar a mencionada 
linha de pesquisa implicaram, também, conhecer as fontes sobre as quais se iria trabalhar. Questões envolvendo tipologías, problemas de tratamento e análise das fontes eram e ainda são fundamentais. Ademais, o descaso dos cartórios para com a preservação das fontes de origem cartorial, impunha (e ainda impõe) que o historiador organizasse sozinho a documentação a ser utilizada por sua pesquisa e se defrontasse com uma rede de códigos e normas não ditas para obter a permissão de acesso às fontes '.

No prefácio do livro de história mais importante sobre o tema produzido no período, Francisco Iglésias afirmava

"E incrivel como um país cuja base foi até ontem quase só a agricultura não tenha aprofundado conhecimento desse aspecto, infra-estrutura de tudo mais. Sem o seu domínio todo o processo peca pelafalta dofundamental. $O$ que é a historiografia referente à agricultura, no entanto? Relativamente pequena, é reduzida a pouco títulos, cuidando do conjunto ou de algum produto, certa técnica, mão-de-obra e outros temas. Tudo de maneira incompleta, às vezes nada além de sugestões. E assuntos básicos são ignorados, como o caso da terra, à espera de pesquisas" (Linhares, 1981:8).

Assim, a pouca participação de historiadores nos debates acerca de temas relacionados ao universo rural, fazia como que se reiterasse a noção de que tal universo era terreno quase exclusivo da sociologia rural. Não era gratuita, portanto, a contribuição marcante proveniente dos sugestivos trabalhos de sociólogos como Maria Silva de Carvalho Franco e José de Souza Martins, autores de dois marcos da historiografia sobre o século XIX: Homens Livres na Ordem Escravocrata, de Carvalho Franco, cuja primeira edição é de 1966 e O Cativeiro da Terra, publicado em 1979. Suas diversas reedições já são por si só indício do impacto de seus estudos na historiografia sobre o tema.

No entanto, à época da publicação dos mencionados livros, os sociólogos eram também pouco atentos à dinâmica do universo rural dos oitocentos. Reiterava-se a noção de que os movimentos rurais - tais como eram entendidos nos anos 70 e 80 do século XX - eram acontecimentos bastante recentes, cuja marca principal era dada pela importante participação das Ligas Camponesas. Presos ainda a uma visão simplificadora sobre o passado, eles minimizavam a

' Para uma análise sobre a alteração do caráter impessoal das regras públicas e introdução dos elementos personalistas e particularizandes ao funcionamento dos cartórios, vide o texto de Ana Paula Miranda (Miranda, 1991). 
contribuição dos homens livres e pobres, e reafirmavam - em cada trabalho que eles não tiveram, no século XIX, "uma razão de ser"2.

Em suma, e apesar dos importantes avanços, os pesquisadores ainda pouco conhecem o universo rural do passado e muito menos as múltiplas dimensões dos movimentos sociais rurais no Brasil dos oitocentos. No campo da história, os estudos sobre o tema não incorporaram enfoques direcionados à análise dos movimentos sociais e da violência no campo. Já na sociologia, os movimentos rurais tem sim uma história, cujo início se dá com a formação das Ligas Camponesas. Ao referirem-se ao passado dos homens livres e pobres, os sociólogos optavam - na maioria das vezes - em definir sua história como uma história de exclusão (Martins, 1983:25). E não somente isso, parte da sociologia ainda considera que o camponês brasileiro sequer tem passado, pois

“O camponês não é uma figura do passado, mas uma figura do presente da história capitalista do país. Classificar a esperança da terra livre como um dado do passado è imputar sentido às lutas camponesas; é admitir que o passado tem uma existência em si mesmo "(Martins, 1983: 16)

Em um dos seus trabalhos mais recentes, o sociólogo Martins reitera o caráter imobilista dos trabalhadores rurais no período anterior à formação das Ligas Camponesas.

"Depois de décadas de imobilismo, quebrado eventualmente pelos movimentos messiânicos e por anárquicas manifestações de banditismo rural(..) os trabalhadores rurais de várias regiões começaram a manifestarse de modo propriamente político" (Martins, 1994: 60).

Para uma nova geração de sociólogos e historiadores, as palavras de Martins soam - ou deveriam soar - como uma chamamento à pesquisa que possa vir a comprovar exatamente o contrário ou, ao menos, relativizar àquela concepção sobre o passado e sobre o homem livre e pobre dos oitocentos. A nosso ver, reconhecer uma característica imobilista aos pobres do campo significa deslêgitimar as experiências de outrora, jogá-las em um outro patamar que não à história, e decidir de uma vez por todas que a história só pertence aos vencedores, pois afinal, "a maior parte da história do passado foi escrita para a glorificação ou, talvez, uso prático dos governantes" (Hobsbawm, 1988: 18).

2 Refiro-me a famosa frase de Maria Silva de Carvalho Franco que afirma: "a agricultura mercantil baseada na escravidão simultaneamente abria espaço para sua existência [do homem livre] e os deixava sem razão de ser”. (Carvalho Franco, 1983, p. 14). 
Não nos deve surpreender, portanto, que os poucos estudos históricos sobre o universo rural quase nunca fazem referência sobre a maneira pela qual os homens do campo procuravam assegurar o seu acesso a terra, quais eram as formas e mecanismos utilizados para a ocupação em terras devolutas e de que maneira elas construíam uma cultura de resistência (Motta, 1998). Não há, de fato, uma história sobre os movimentos sociais rurais, sobre os conflitos de terra ocorridos no passado, e muito menos, uma reflexão sobre questões que envolvem concepções de justiça e direitos. Em outras palavras, as perguntas sugeridas por uma análise pelo viés thompsoniano eram e ainda são marginais. No entanto, ainda que periféricas na produção acadêmica, estas indagações nos fazem refletir sobre várias e interessantes "portas de entrada" para a pesquisa sobre os movimentos rurais do século XIX. Em certo sentido, aquelas perguntas nos permitem ainda recuperar as contribuições de Alberto Passos Guimarães, que a despeito da defesa de que o Brasil dos anos sessenta do século XX apresentava características feudais, escrevera:

\footnotetext{
“Ao atacar de frente o todo-poderoso sistema latifundiário, ao violar suas draconianas instituições, a posse passa à história como a arma estratégica de maior alcance e maior eficácia na batalha secular contra o monopólio da terra (...) Intrusos e posseiros foram os precursores da pequena propriedade camponesa(...) (Guimarães, s/d:38).
}

Uma análise sobre a noção do direito a terra nos ajuda a refletir sobre o tema. Tal noção nos remete a uma discussão sobre a maneira pela qual devemos entender a expansão territorial e como ela é operada pelos grandes fazendeiros. Ser senhor de terras no Brasil dos oitocentos, mas também de certa forma no Brasil de hoje, implica não se submeter às determinações legais no sentido de medir e demarcar sua terra. Os fazendeiros, sempre que puderam, ocuparam terras devolutas limítrofes a sua fazenda, transformando-as em parte do seu domínio. Além disso, nunca é demais registrar que os métodos escusos de falsificação de documentos, da mágica que transforma 50 hectares em 5.000 e de invenção de cadeias sucessórias (que produz um filho natural em inventários post-mortem de fazendeiros solteiros e sem filhos) são métodos e estratégicas que também tem sua história.

Mas o que aqui importa é a imperiosa necessidade de se pensar a expansão territorial enquanto processo, para podermos ter alguma condição de compreender como os pequenos posseiros, mesmo derrotados, procuravam limitar a expansão territorial dos fazendeiros, ao negarem que aqueles eram senhores epossuidores ${ }^{3}$

\footnotetext{
${ }^{5}$ Este é um termo de época, recorrente nos processos de Embargos, quando os fazendeiros buscavam expulsar os "invasores". (Motta, 1998a)
} 
das terras por eles ocupadas. Logo, para o fazendeiro do século XIX não bastava somente dizer que era dono da terra por ele invadida, era preciso que outros o reconhecem como tal. Se os pequenos posseiros haviam sido os primeiros a derrubar matas virgens e a plantar gêneros alimentícios, como alegavam nos processos de embargo em que eram sempre os réus (Motta, 1998), isso significava que eles procuraram limitar a expansão territorial do fazendeiro e, nesse sentido, só o reconheciam como senhor de terras de uma área específica, cuja ocupação era reconhecida por aqueles.

Ao se transformarem em réus de um processo, ao verem suas casas e seus cultivos serem queimados por força de um auto de embargo, eles podiam perceber concretamente que o mero apossamento não lhe garantia o domínio e sua manutenção na área ocupada. Tinham ao menos duas alternativas: aceitavam a condição de agregados do fazendeiro, assegurando o uso de parcelas de terra, mas reconhecendo o fazendeiro como senhor e possuidor da área ocupada; ou insistiam em ser reconhecidos como posseiros que diante do questionamento do seu direito a terra, passaram a lutar pela afirmação de sua condição de legítimos ocupantes. Esta última decisão significava não estar disposto a de lá sair tranqüilamente. No entanto, apesar do processo de embargo permitir - no século XIX - a queima de toda colheita do posseiro e destruição de suas benfeitorias, não era raro que os pequenos posseiros insistissem em continuar cultivando a terra em litígio, argumentando que elas eram suas por serem os primeiros ocupantes. Assim, mesmo perdedores na maior parte dos processos, eles insistiam em se fazer ouvir, reiterando uma determinada visão de direito a terra, ainda pouco conhecida por nós.

$\mathrm{O}$ que reafirmamos é que as evidências apontam insistentemente para o fato de que mesmo derrotados nos processos de embargo e despejos abertos pelos fazendeiros, os pequenos posseiros tentaram assegurar uma parcela de terra, construíram estratégias que não podem ser identificadas como uma expressão de seu imobilismo.

Esta última argumentação esbarra, a princípio, no fato de que estamos a falar do Brasil do oitocentos, cuja fronteira agrícola estava aberta em grande parte do território nacional. Ё preciso se perguntar, antes de tudo, porque muitos posseiros não decidiam migrar, ir em busca de regiões ainda não desbravadas. Em outras palavras, porque muitos deles preferiam lutar por um quinhão de terra, objeto de cobiça de um fazendeiro poderoso, cujo poder ia muito além da porteira da fazenda.

Se seguirmos esta última linha de raciocínio, devemos então concluir que no Brasil do século XIX as inúmeras terras livres, passíveis de serem ocupadas por todos, inibiam a existência de conflitos agrários. Por conseqiiência, tais conflitos 
só podem ser pensados enquanto uma realidade dos tempos mais recentes, resultado direto do fechamento da fronteira. Assim sendo, as evidências acerca de ocorrências de conflitos no século XIX foram demasiadamente enfatizadas em texto anterior, o que significa afirmar que a revolta dos arrendatários da Fazenda do Barão de Piabanha, ocorrida em 1858, foi a tão falada exceção que confirma a regra(Motta, 1998a). Da mesma forma, os discursos dos senadores relativos às disputas pela posse da terra quando da aprovação da Lei de Terras, eram apenas pura retórica do poder. Assim, o arrazoado do senador pelo Ceará, Manoel José de Albuquerque, em 1848, é tão somente um exemplo emblemático do que não ocorria.

"De muitos anos estou penetrado da necessidade de adotar-se uma medida que ponha termo as milhares de contendas que todos os dias se levantam entre posseiros e sesmeiros, entre posseiros mais antigos e mais modernos contra os mesmos sesmeiros, por causa dos limites e confrontações de suas respetivas sesmarias" (apud, Motta, 1998a).

Talvez também se esteja exagerando ao dar importância a um documento de poucas páginas onde pequenos posseiros, multados por não terem registrado suas terras em razão da exigência do registro paroquial, são listados numa relação onde o Pároco da Freguesia de Nossa Senhora da Conceição de Paratymirim solicita, em 1859, que o governo lhes dê novo prazo para o registro, uma vez que são muito pobres e possuem numerosa família ${ }^{4}$. Dessa documentação, podemos inferir duas possibilidades. A primeira era a existência de um padre preocupado com a pobreza local, resoluto em interferir mais diretamente na questão dos registros de terra. A segunda não nega a primeira, mas ressalta também o reconhecimento prévio de uma comunidade de pequenos posseiros pobres e cientes da necessidade de registrar suas pequenas parcelas de terra. A conjunção, e não a exclusão de uma das duas alternativas permite-nos ressaltar a multiplicidade de situações vividas no universo rural de outrora.

Insiste-se aqui em afirmar que a realidade rural é muito mais complexa do que tendemos a acreditar. Os homens livres e pobres procuravam assegurar o seu acesso a terra, pois sabiam que migrar para outras regiões era um risco ainda maior, não somente em relação ao desconhecido, mas sobretudo porque a migração implicava em custos. Em primeiro lugar, custos económicos, ou seja, a necessidade de dispor de um pequeno, mas necessário capital para saírem

${ }^{4}$ Arquivo Público do Estado do Rio de Janeiro. Rellação dos Senhores possuidores de terras da Freguesia de Nossa Senhora da Conceição de Paratymirmi que se achão multados, 1859. 
do local em que se encontravam, sobreviver, em suma, até encontrarem um novo lugar para desbravar e posteriormente plantar. Também existiam custos sociais, a perda das relações sociais que tinham ou desejavam ter com a comunidade na qual procuravam se estabelecer. Migrar significaria romper elos já consolidados ou em vias de se consolidar.

O sentimento de justiça de pequenos posseiros, no caso, de injustiça, era resultado de uma certeza: eles haviam sido os primeiros a ocupar o local objeto de disputa. A nosso ver, o processo de ocupação de terras pelo apossamento praticado pelos fazendeiros permitia que outros agentes sociais reconhecessem o seu direito à ocupação também pelo sistema de apossamento, concretizando, assim, um direito vivido (Bourdieu, 1989).

Assim sendo, a noção de justiça não era calcada em nenhuma abstração sobre os princípios definidores do que seja justo, mas era resultado da experiência que adquiriram na sua relação com a terra, fruto do trabalho diário e estafante para derrubar uma mata, plantar, cuidar e esperar pelos resultados de sua labuta. Mas também na experiência adquirida com outros componentes da comunidade, por exemplo, com aqueles que já haviam conseguido uma pequena parcela de terra, antes em matas viigens. Na sua relação com a comunidade, eles se esforçavam em serem reconhecidos como os donos de suas terras, às vezes, em área objeto de litígio. Para tanto, os argumentos que utilizavam para reafirmar sua condição de posseiros eram resultado de uma cultura e de uma prática social que consideravam legítimo o princípio da primeira ocupação, do fato que eram eles, e não qualquer outro, que haviam derrubado a mata virgem e realizado o primeiro cultivo. Ao invés de se submeterem aos desmandos de um fazendeiro, muitos procuraram se defender, respondendo às acusações de que eram vítimas.

É claro que não estamos aqui afirmando que todos os pequenos posseiros de outros tempos eram indivíduos corajosos, sempre dispostos a desafiar o poder de um senhor de terra. Mas, mesmo que consideremos que a sociedade rural do passado era marcada pelos desmandos e violência do fazendeiro, havia sempre uma possibilidade de contestação que não deve ser descartada. Se conseguirmos escapar de uma visão numérico-estatística da participação dos indivíduos em movimentos sociais, ou melhor, se entendermos os movimentos sociais em toda a sua dinâmica,isso talvez nos ajude a recuperar a historicidade dos movimentos sociais rurais do Brasil, sem cair na armadilha de considerá-los apenas dentro de marcos históricos pontuais, e, por conta disso, reducionistas de uma realidade mais ampla. Se é importante marcar os processos históricos, pontuar os movimentos sociais nos quadros, por exemplo, das rupturas institucionais (recorde-se aqui nas Ligas Camponesas e no golpe de 1964 no Brasil) é preciso também recuperar a tênue linha de continuidade. 
$\mathrm{Na}$ instigante apresentação do livro de Giovanni Levi, revel afirmou:

"Le rôle de l'observateuer n'est pas de lire la réalité qu 'il étudie avec les instruments généralement simplifiants qu 'il a reçus (simplifiants, à vrai dire, parce qu 'il les a reçus, les plus souvent). Il lui revient au contraire d'enrichir le réel en introduisant dans $V$ analyse le plus grand nombre de variables, sans renoncer pourtant à y repérer des régularités". (Levi, 1985: XXIV-XXV).

Nos avanços e retrocessos, na dinâmica da luta pela posse da terra no Brasil, há uma tradição cultural que explica quais são os elementos através dos quais os seres humanos legitimam o seu acesso a terra ou de outrem. Logo, se para os fazendeiros a ocupação das terras devolutas, a incorporação das mesmas como parte de seus domínios, faziam e fazem ainda parte de uma visão de que ser senhor de terra implica poder expandi-la sem se submeter a nenhuma determinação de terceiros; para os pequenos posseiros, há também uma tradição que justifica a legitimidade da primeira ocupação como forma de aquisição de uma parcela de terra. Ambos, muitas vezes navegam no mesmo pressuposto: alegam serem os primeiros a ocupar o quinhão em disputa. Mas se para o fazendeiro, tal pressuposto está inserido numa concepção patrimonial acerca da terra, para os pequenos posseiros ele está relacionado à possibilidade de exercer uma liberdade efetiva, na reprodução de sua unidade familiar, sem a dependência para com um senhor de terras.

Nós ainda temos muito a conhecer acerca da história dos movimentos sociais no Brasil. Talvez seja animador saber que tal ignorância, no entanto, não se restringe a este país. Ela também esteve presente na historiografia inglesa, em fins dos anos 60, quando veio à luz o trabalho de Hobsbawm e George Rude, Capitão Swing, acerca das revoltas rurais na Inglaterra do início do século XX.

"Na verdade nosso conhecimento sobre o mundo dos trabalhadores rurais no século XIX tem muitas falhas, mas nenhuma delas é mais chocante do que a total ignorância sobre as formas de descontentamento agrário ocorridas entre o levante de 1830 e o surgimento do movimento sindicalista agrário no início dos anos setenta. Os historiadores dos movimentos sociais parecem ter reagido com relação à inquietação agrária da mesma forma como outros habitantes urbanos de tendência esquerdista a qual a maioria deles pertencia por tradição - isto é, em geral só tomavam consciência do movimento quando este assumia uma forma e proporção ampla ou dramática o bastante para se tornar notícias nos jornais da cidade. (Hobsbawm, 1982: 58). 
Há que se destacar, porém que trabalhos mais recentes têm contribuído para construir ou reconstruir uma análise mais densa acerca dos movimentos rurais do passado. Para tanto, é preciso destacar que uma história com este perfil - em grande parte de inspiração thompsoniana - busca compreender o passado à luz das contribuições de disciplinas sociais, em particular a antropologia. Ao romper com a primazia do económico em detrimento dos aspectos ligados às normas e a cultura, a história social - segundo Thompson - incorpora as múltiplas dimensões do social, destacando o papel da experiência na compreensão das contradições do processo histórico. Tais contradições são, por sua vez, o conflito entre o modo de viver e as normas da comunidade local e ocupacional da sociedade 'envolvente' (Thompson, 2001:262) E ainda, o conflito seria então "as maneiras pelas quais o caráter essencialmente explorador das relações produtivas se toma uma experiência vivida" (Idem).

Ao dissipar o caráter estático da noção de classe social - de viés althusseriano a história social destaca o papel da luta de classe enquanto conceito primordial para se compreender as experiências históricas de indivíduos e grupos. São as lutas que constroem as classes, posto que "as classes se delineia segundo o modo como os homens e mulheres vivem suas relações de produção e segundo a experiência de suas situações determinadas, no interior do conjunto de suas relações sociais, com a cultura e as expectativas a eles transmitidas e com base no modo pelo qual se valeram dessas experiências em nível cultura" (Ibidem: 277). Ao apoiar-se num intenso cruzamento de fontes de diversas origens, a história social revela-se como um campo fértil de análise para a reconstmção história do campesinato, pois objetiva reconstruir a história dos movimentos sociais e das lutas pela terra a partir de uma metodologia que rompe com esquemas pré-concebidos, reconstituindo ou buscando reconstruir o passado em suas complexas matrizes.

Minhas pesquisas sobre os conflitos agrários dos oitocentos revelam que há estratégias de sobrevivência muito complexas, jogos de poder de numerosas faces (Motta, 1998a; 1998b). Para o fazendeiros, deter a ousadia de pequenos posseiros poderia significar ter que mudar o nome de sua fazenda, e apagar da memória um nome antigo, atrelado na memória como um lugar de conflito (Motta, 1998c).

Deve-se registrar também a pesquisa de Castro Neves que analisou processo de formação periódica da multidão como sujeito político coletivo. Influenciado pela bibliografia da nova esquerda britânica, o autor discutiu a consolidação de uma tradição de luta da multidão no Ceará, que se formou ao longo dos anos que se seguem à seca de 1877 e se consolida na década de 1950. (Castro Neves, 2000).

Estudos ainda em andamento têm revelado aspectos pouco explorados pelos historiadores. No âmbito do Núcleo de Referência Agrária, da Universidade 
Federal Fluminense, jovens pesquisadores estão identificando e analisando conflitos agrários nos séculos XVIII e XIX, concepções de direito e justiça em sua relação com a apropriação territorial.

Toda esta discussão acerca da produção acadêmica sobre os movimentos rurais dos oitocentos talvez nos ajude a pensar que é chegada a hora de aproximarmos estudos ainda hoje paralelos. Martins está certo ao afirmar em recente artigo que "é preciso transgredir as imunidades estamentais e corporativas de que a sociologia rural se cercou, faze-la dialogar mais, comungar mais e aprender mais com a História, a Literatura, a Geografia, a Antropologia"(Martins, 2000: 9).

Mas o diálogo deve ser de mão dupla, pois os historiadores do oitocentos também devem se aproximar dos debates da Sociologia Rural, reconhecendo que o tema dos movimentos rurais pode ser um terreno de múltiplas contribuições. Romper os muros que nos cercam talvez seja a primeira de nossas tarefas.

Quem sabe possamos enfim nos permitir perguntar porque o passado dos movimentos rurais foi tão esquecido. Como se deram as regras de exclusão, supressão ou repressão sobre os conflitos de terra de outrora? (Burke, 1992) Qual a relação desta amnésia com a consolidação de uma visão sobre o homem do campo como dócil, passivo e ignorante?

Para desconstruir esta memória, é preciso então entender que a história "é a reconstrução sempre problemática e incompleta do que não existe mais" (Nora, 1993: 9). Significa afirmar que, ao contrário da memória, a história busca uma representação crítica do passado. Assumir, portanto, a complexidade da história sobre os movimentos rurais é a segunda de nossas tarefas. Estar ciente da dificuldade de construí-la, afasta-nos, mas não elimina, o perigo de construirmos apenas memórias.

Os elementos constitutivos da memória reiteram que a memória é um fenômeno socialmente construído. Isso também nos permite afirmar que a memória e a identidade "são valores disputados em conflitos sociais" (Pollack, 1992:207)-. Portanto, é preciso estar atento ao fato de que sua construção implica não somente lembrar, como também esquecer.

O processo de construção de memórias pressupõe escolhas entre os fatos do passado, que - por uma razão ou outra - determinado grupo considera que devam ser lembrados/rememorados. Ao fazer escolhas, o grupo também esquece e faz esquecer outros acontecimentos.

É verdade que "sem o esquecimento, a memória humana é impossível" (Menezes, 1992: 16). Mas quando falamos de grupos sociais, devemos estar cientes de que existem "projetos de esquecimentos", coisas e fatos que não devem ser lembrados, sob pena de ser ameaçada a unidade do grupo, questionada sua identidade, fragilizando e/ou colocando em questão o interesse comum. 
Assim, a terceira de nossas tarefas é tentar identificar projetos de esquecimento, presentes, por exemplo, na mídia, nos relatórios oficiais sobre luta pelo acesso à terra e - porque não dizer - em parte da produção acadêmica sobre conflitos rurais. Assim, talvez venhamos a descobrir que longe de ser apenas um certo descuido da historiografía, o pouco peso dado aos movimentos rurais do século passado (a ação coletiva dos pobres do campo) tenha sido o resultado - não previsível - de um esforço de se consolidar uma tradição inventada: povo passivo, ausência de conflito.

\section{Referências Bibliográficas}

Arquivo Público do Estado do Rio de Janeiro. Rellação dos Senhores possuidores de terras da Freguesia de Nossa Senhora da Conceição de Paratymirmi que se achão multados, 1859.

BARRINGTON MOORE Jr. - Injustiça. As bases sociais da obediência e da revolta. Rio de Janeiro, Brasiliense, 1978.

BOURDIEU, Pierre - "A força do direito. Elementos para uma sociologia do campo jurídico”. O Poder Simbólico. Rio de Janeiro, Editora Bertrand Brasil, 1989.

BURKE, Peter - "A história como memória social”. O Mundo como Teatro. Lisboa, Difel, 1992..

CASTRO NEVES, Frederico - A Multidão e a História. Saques e outras ações de massas no Ceará. Rio de Janeiro, Relume Dumará, 2000.

CHALHOUB, Sidney - Visões da Liberdade. São Paulo, Companhia das Letras, 1990. CHALHOUB, Sidney - Cidade Febril. Cortiços e Epidemias na Corte Imperial São Paulo, Companhia das letras, 1996.

GORENDER, J. - A Escravidão reabilitada. São Paulo, Ática, 1990.

GUIMARÃES, Alberto Passos - Quatro Séculos de Latifúndio. Rio de Janeiro, Paz e Terra, s/d,

HOBSBAWM, Eric - "A Outra História - Algumas reflexões." in: KRANTZ, Frederick - A Outra História. Ideologia e Protesto Popular nos século XVII a XIX. Rio de Janeiro, Jorge Zahar, 1988.

HOBSBAWM, Eric \& RUDÉ, George - Capitão Swing. Rio de Janeiro, Francisco Alves, 1982.

HOBSBAWM, Eric - "Introdução: A Invenção das Tradições”. HOBSBAWM, Eric \& RANGER, Terence (orgs) - A Invenção das Tradições. Rio de Janeiro, Paz e Terra, 1984.

LARA, Silvia - "Escravidão no Brasil: Balanço Historiográfico" e GORENDER, Jacob "A Escravidão Reabilitada" in Dossiê Escravidão. L.P.H Revista de História vol. 3, no 1, 1992. 
LINHARES, Maria Yedda Leite \& SILVA, Francisco Carlos Teixeira da - História da Agricultura Brasileira. Combates e Controvérsias. São Paulo, Brasiliense, 1981.

MARTINS, José de Souza - Os camponeses e a política no Brasil. As lutas sociais no campo e seu lugar no processo político. 2a edição. Petrópolis, Vozes, 1983.

MARTINS, José de Souza - O Poder do Atraso. Ensaios de Sociologia da História Lenta. São Paulo, Hucitex, 1994.

MARTINS, José de Souza - "O futuro da sociologia rural e sua contribuição para a qualidade da vida rural" in Estudos Sociedade e Agricultura Rio de Janeiro, Universidade Federal Rural do Rio de Janeiro/CPDA, número 15, outubro de 2000.

MENEZES, Ulpiano Bezerra de - “A História, cativa da Memória? Para um mapeamento da memória no campo das Ciências Sociais”. Revista Instituto de Estudos Brasileiros. São Paulo, 1992, p. 14.

MOTTA, Márcia Maria Menendes - Pelas Bandas d'além (fronteira fechada e arrendatários escravistas em uma região de policultura. Niterói, UFF, Dissertação de Mestrado, 1989.

MOTTA, Márcia Maria Menendes Motta - Nas Fronteiras do Poder. Conflito e Direito à Terra no Brasil do século XIX. Rio de Janeiro, APERJ/Vício de Leitura, 1998a.

MOTTA, Márcia Maria Menendes - "Caindo por terra (historiografia e questão agrária no Brasil do século XIX" in: GIRBAL-BLACHA y VALENCIA, Marta Agro, Tierra y Política. Debates sobre la História Rural de Argentina y Brasil. La Plata, Editora da UNLP, 1998 b.

MOTTA, Márcia Maria Menendes - "Jogos da memória: conflito de terra e amnésia social" in: Revista Tempo. Niterói/Rio de Janeiro; Departamento de História da UFF/Sette Letras, 1998c.

MOTTA, Márcia Maria Menendes - “Agrilagem como legado”in MOTTA, Márcia \& PIÑEIRO, Théo Lobarinhas. Herança. Voluntarismo e Universo Rural. Rio de Janeiro, Vício de Leitura, 2001, volume 1.

NORA, Pierre - "Entre Memória e História. A problemática dos lugares". Projeto História. São Paulo, no 10, dezembro de 1993.

POLLACK, Michael - "Memória e Identidade Social”. Revista Estudos Históricos.

Rio de Janeiro, vol. 5, n. ${ }^{\circ} 10,1992$.

REVEL, Jacques - "L'histoire au ras du sol” in: Levi, Giovanni - Le pouvoir au village. Paris, Gallimar, 1985.

SILVA, Francisco Carlos Teixeira da - Camponeses e Criadores na Formação Social da Miséria (1820-1920). Niterói, UFF, Dissertação de Mestrado, 1981. 
SOARES, Carlos Eugênio - A Negrada Instituição. Os capoeiras na Corte Imperial. Rio de Janeiro, ACCESS, 1999.

SOARES, Carlos Eugênio - A capoeira escrava e outras tradições rebeldes no Rio de Janeiro (1808-1850). São Paulo, Campinas, Ed. Unicamp, 2001.

THOPMSON, E. - Tradición, Revuelta e Conscienda de Clase. Barcelona, Editorial Crítica, 1979.

THOMPSON, E. - Senhores e Caçadores. Rio de Janeiro, Paz e Terra, 1987.

THOMPSON, E. - "Folclore, Antropologia e Historia Social" in: NEGRO, Antonio Luigi \& SILVA, Sergio (org) - As peculiaridades dos ingleses $e$ outros artigos. Campinas, UNICAMP, 200.

THOMPSON, E. - Costumes em comum. Rio de Janeiro, Companhia das Letras, 1998. 